GRADIATION\&APPLICATIONS

ISSN 2466-4294 (online) | rad-journal.org

Vol. 3 | Issue 1 | pp. 18-22, 2018

doi: 10.21175/RadJ.2018.01.004

Original research paper

\title{
THE REGISTRATION OF CS-134 BY GAMMA DETECTOR PAIRS AT AN ANGLE OF $90^{\circ *}$
}

\author{
Nikola Svrkota ${ }^{1}$, Jelena Mijuškovič ${ }^{2}$ Nevenka M. Antoviće ${ }^{* *}$ \\ ${ }^{1}$ Centre for Ecotoxicological Research, Podgorica, Montenegro \\ ${ }^{2}$ Faculty of Natural Sciences and Mathematics, University of Montenegro, Podgorica, Montenegro
}

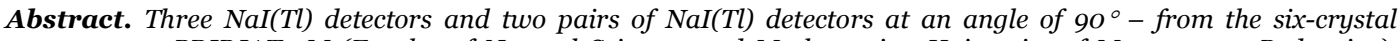
spectrometer PRIPJAT-2M (Faculty of Natural Sciences and Mathematics, University of Montenegro, Podgorica), were used to determine registration efficiencies for the most intense gamma rays in de-excitation of $134 \mathrm{Ba}$, following beta minus decay of ${ }^{134} \mathrm{Cs}$. The ${ }^{134 C s}$ liquid calibration standard was used for acquiring spectra over 18 ooo s real time in the energy range (200-300o) $\mathrm{keV} \mathrm{-} \mathrm{in} \mathrm{the} \mathrm{integral,} \mathrm{non-coincident} \mathrm{and} \mathrm{mode} \mathrm{of} \mathrm{double} \mathrm{gamma-gamma}$ coincidences. All the spectra from individual detectors and detector pairs in all the counting modes clearly showed peaks at the 605 and $796 \mathrm{keV}$. The experimental registration efficiency of the $605 \mathrm{keV}$ gamma ray by individual detectors in different modes of counting was found to be with an average of o.055 (integral), o.o32 (non-coincident) and 0.021 (double coincidences), whilst in the case of two detector pairs - 0.112 (integral), o.o65 (non-coincident) and 0.042 (double coincidences). In regards to the $796 \mathrm{keV}$, average detection efficiencies were o.04 (integral), o.026 (non-coincident) and 0.013 (double coincidences) - in the case of individual detectors, and o.o76 (integral), o.o48 (non-coincident) and 0.026 (double coincidences) - for the detector pairs. Obtained results are baselines for the future development of the coincidence method for ${ }^{134 C s}$ measurement - using multidetector systems with measuring geometry close to $4 \pi$, with the $796 \mathrm{keV}$ photopeak in a coincidence mode as appropriate for $134 \mathrm{Cs}$ detection in a sample containing ${ }^{137} \mathrm{Cs}$ and decay products of ${ }^{226} \mathrm{Ra}$ and ${ }^{232} \mathrm{Th}$.
\end{abstract}

Key words: $\mathrm{Cs}$-134, $\mathrm{NaI}(\mathrm{Tl})$ detector pairs, gamma coincidences

\section{INTRODUCTION}

In European countries, where ${ }^{137} \mathrm{Cs}$ was deposited significantly in 1986 (after the Chernobyl accident), the global fallout could be separated from the Chernobyl fraction by using ${ }^{134} \mathrm{Cs}$, i.e., the ${ }^{134} \mathrm{Cs} /{ }^{137} \mathrm{Cs}$ ratio (significantly different in the fallout from those two sources). Determining activities of two cesium isotopes in various samples and developing methods for their simultaneous measurements (see, for example, [1]), are still important, particularly after the accident at the Fukushima Daiichi Nuclear Power Plant. Therefore, measurements of ${ }^{134} \mathrm{Cs}$ and ${ }^{137} \mathrm{Cs}$ activity concentration in environmental samples are of considerable radioecological interest.

Cesium-134, a fission product with a half-life of 2.1

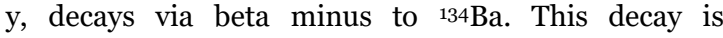
accompanied by the emission of $11 \gamma$-rays (those with an intensity above $1 \%$ are given in Table 1 [2]). Among these gamma rays, the most intense have the energies of $604.72 \mathrm{keV}$ and $795.86 \mathrm{keV}$ (i.e., $605 \mathrm{keV}$ and 796 $\mathrm{keV}$, respectively), and they can be used to register ${ }^{134} \mathrm{Cs}$ in an environmental sample, in a standard gamma spectrometry by the systems equipped with one detector. At the same time, environmental samples contain natural radionuclides ${ }^{226} \mathrm{Ra}$ and ${ }^{232} \mathrm{Th}$ and their decay products, whose decays are followed with the emission of gamma rays with comparable energy (taking into account the energy resolution), e.g. 609 $\mathrm{keV}$ and $583 \mathrm{keV}$, etc., as well as ${ }^{137 \mathrm{Cs}}(662 \mathrm{keV}$ gamma rays). Therefore, some regions of gamma spectra could be recognized as unresolved peaks of a few $\gamma$-rays.

Table 1. The most intense gamma rays following beta minus decay of ${ }^{134} \mathrm{Cs}$ [2]

\begin{tabular}{|c|c|}
\hline $\mathrm{E}_{\gamma}(\mathrm{keV})$ & $\mathrm{I}_{\gamma}(\%)$ \\
\hline 475.365 & 1.479 \\
563.246 & 8.342 \\
569.330 & 15.368 \\
604.720 & 97.63 \\
795.86 & 85.47 \\
801.950 & 8.694 \\
1167.967 & 1.791 \\
1365.194 & 3.019 \\
\hline
\end{tabular}

\footnotetext{
* The paper was presented at the Fifth International Conference on Radiation and Applications in Various Fields of Research (RAD 2017), Budva, Montenegro, 2017.

antovicn@yahoo.com
} 
To determine the activity of ${ }^{134} \mathrm{Cs},{ }^{137} \mathrm{Cs}$ and ${ }^{90} \mathrm{Sr} /{ }^{\circ} \mathrm{Y}$ in a mixture, a new coincidence method was proposed recently [1], as well as the spectrometer with plastic for beta, and $\mathrm{NaI}(\mathrm{Tl})$ detector - for gamma ray detection.

The decay scheme ${ }^{134} \mathrm{Cs}$ beta minus, i.e., de-

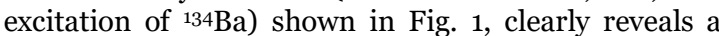
possibility to use gamma-gamma coincidences for ${ }^{134 \mathrm{Cs}}$ registration and determination of its activity concentration in a sample. Many gamma rays, in deexcitation of ${ }^{134} \mathrm{Ba}$ nuclei, are in cascade transitions (2(or more)-fold ones), and their registration is possible using a multidetector spectrometer and appropriate method. Among two-fold cascades, the most intense are those with the same last transition with the energy of $605 \mathrm{keV}$, in particular $796 \mathrm{keV}+605 \mathrm{keV}$, between the excited levels $1400.591 \mathrm{keV}$ and $604.723 \mathrm{keV}$, and from the excited level $604.723 \mathrm{keV}$ to the ground state of ${ }^{134} \mathrm{Ba}$, respectively.

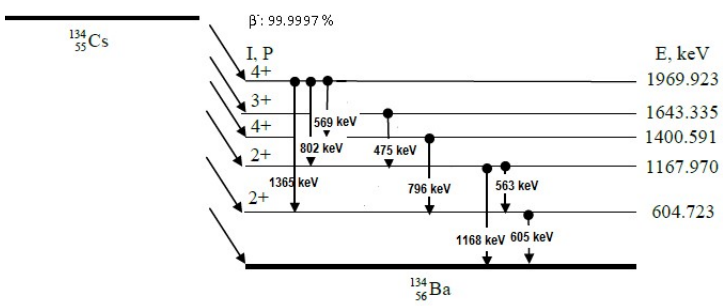

Figure 1. De-excitation of 134Ba nucleus

It has been shown in many studies, various coincidence modes, as well as Compton suppression, are suitable for low-level gamma spectrometry, and expressed advantages in different situations (see, for example, [3]).

In order to develop a coincidence method for ${ }^{134} \mathrm{Cs}$ measurements by the multidetector $(\mathrm{NaI}(\mathrm{Tl}))$ system with geometry registration close to $4 \pi$, based on registration of gamma-gamma coincidences, some test experiments have been performed recently, using the 6-crystal spectrometer PRIPYAT [4] (PRIPYAT-2M located at the Faculty of Natural Sciences and Mathematics, University of Montenegro, Podgorica). The registration of ${ }^{134} \mathrm{Cs}$ by the $\mathrm{NaI}(\mathrm{Tl})$ detector pair at the angle of $180^{\circ}$ (from the geometric spectrometer centre to the detectors centers) can be seen in ref. [5]. In the present study, we consider its registration by $\mathrm{NaI}(\mathrm{Tl})$ detector pairs at the angle of $90^{\circ}-$ in three different modes of counting.

\section{EXPERIMENTAL}

The PRIPYAT-2M spectrometer (Fig. 2), whose dimensions are $250 \mathrm{~cm} \mathrm{x} 145 \mathrm{~cm} \mathrm{x} 186 \mathrm{~cm}$, consists of six identical scintillation units ( $\mathrm{NaI}(\mathrm{Tl})$ crystal: $15 \mathrm{~cm} \mathrm{x}$ $10 \mathrm{~cm}$ ), passive shielding (iron and lead up to $15 \mathrm{~cm}$ ), electronics in the CAMAC standard. A measuring chamber is a cube of a $17.5 \mathrm{~cm}$ side. The spectrometer has solid angle of $\sim 0.7 \times 4 \pi \mathrm{sr}$, resolution time for coincidences $40 \mathrm{~ns}$, and the possibility to register coincidences with the multiplicity from two- to six-fold.
An average energy resolution of the detectors was found to be $9.5 \%$ (for the $662 \mathrm{keV}$ gamma line).

A schematic diagram of the PRIPYAT-2M is given in Fig. 3a, whilst a detector pair - in Fig. 3b.

Data acquisition, processing, presentation and archiving, are provided by the software PRIP, which also provides calibration of the spectrometric channels (energy, photoefficiency, total detection efficiency), selecting the coincidence-fold ranges and energy range. It gives spectra from individual detectors in the selected mode of counting, sum spectra, as well as information about registered energy, photopeak counts etc., after subtraction of the corresponding background (acquired in the same mode of counting), peak fitting, and summing (in the case of sum spectra).

Available modes of counting at the PRIPYAT spectrometer are

(a) integral mode ([1_6]) - registration of all signals/pulses, coincident and non-coincident,

(b) non-coincidence mode ([1_1]) - registration of non-coincident signals only,

(c) two coincidence modes: one ([2_6]) registration of all coincident signals coming from the detectors without their separation, and the other when $\gamma$-spectra of coincident signals (separate two-, three-, four-, five-, and six-fold) are produced simultaneously. In the last one, there is a possibility to select a coincidence range. So, if the range of 2 is selected, that means, for each detector, the spectrum of non-coincident signals, as well as the spectrum of double coincidences ( $\gamma$-ray registered simultaneously, respecting the spectrometer resolving time, with the registration of another $\gamma$-ray by any other detector) are produced simultaneously.

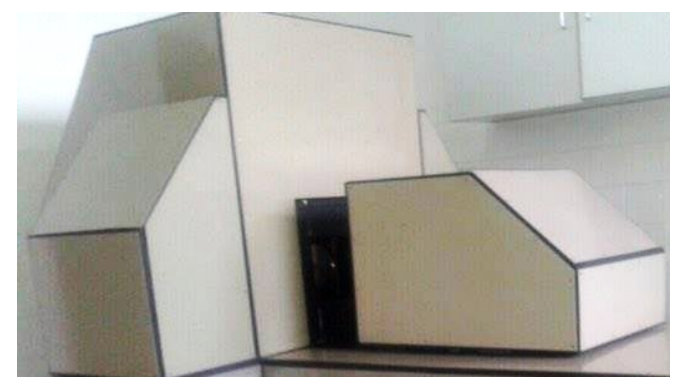

Figure 2. Spectrometer PRIPYAT-2M

As can be seen from Fig. 3a, number of the detector pairs in the PRIPYAT system is 15 (12 with the angle between detectors of $90^{\circ}$, and 3 - with the angle of $180^{\circ}$ ). The detectors 4,5 and 6 , as well as the pairs 45 and 46 are considered here.

The ${ }^{134} \mathrm{Cs}$ source, volume (1 L) liquid calibration standard 9031 - OL - 471/o6 (Czech Metrology Institute, $542.4 \mathrm{kBq}$ - 25/08/2006) was used for acquiring spectra (activity at the day of measurements - $21.42 \mathrm{kBq}$ ) over 18 ooo $\mathrm{s}$ real time. In the integral ([1_6]) mode, live measuring time was $3521.2 \mathrm{~s}$. In the mode 6 , when non-coincident, and spectra of two-, three-, four-, five-, and six-fold coincidences were produced simultaneously live measuring time was 
3519.1 s. The source spectra (in the integral, noncoincident and the mode of double coincidences), were analyzed after the background subtraction (3530 $\mathrm{s}$ in the integral, and $3520 \mathrm{~s}$ live measuring time in the coincidence mode).

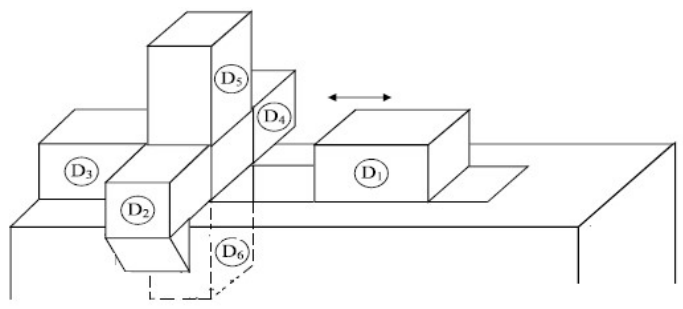

a)

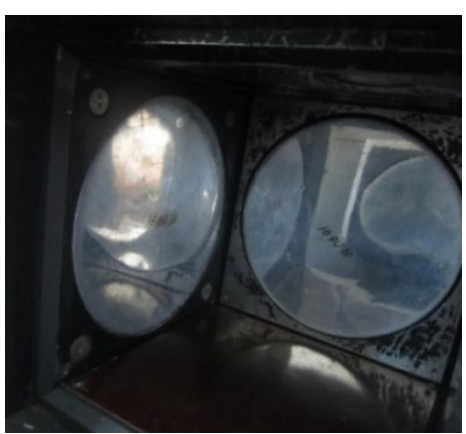

b)

Figure 3. Schematic diagram of the PRIPYAT-2M (a), detector pair (b)

\section{SPECTRA}

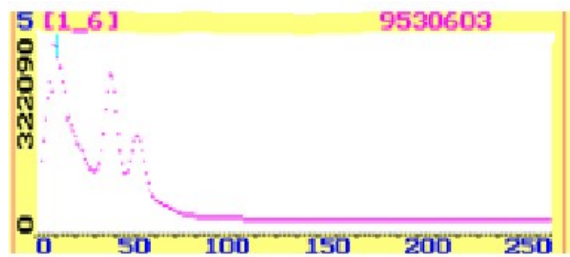

a)

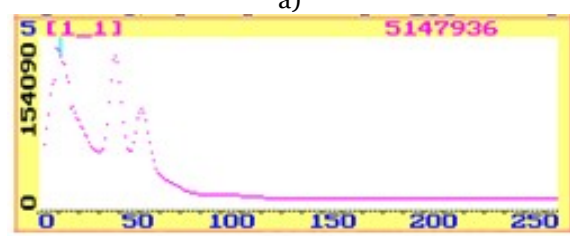

b)

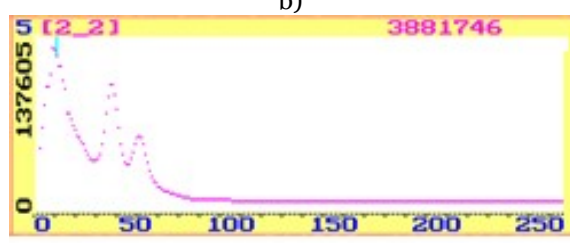

c)

Figure 4. Spectra ${ }^{134 \mathrm{Cs}}$ (peaks $605 \mathrm{keV}$ and $796 \mathrm{keV}$, around channel 50), detector 5: in the integral ([1_6]) mode of counting (a), in the non-coincident ([1_1]) mode of counting

(b), in the mode of double coincidences ([2_2]) (c)
The ${ }^{134} \mathrm{Cs}$ spectra from individual detectors contain pronounced photopeaks of the $605 \mathrm{keV}$ and $796 \mathrm{keV}$ gamma rays - in all the modes of counting. As an illustration, spectra from detector 5 in the whole energy range, are given in Fig. 4. The number of counts in the peak regions ( $605 \mathrm{keV}$ and $796 \mathrm{keV}$ ) was 2454 435 and 1614 062, respectively (in the integral mode), 1343742 and 972 510, respectively (in the noncoincident mode), and 1016493 and 585 572, respectively (in the mode of double coincidences).

"Peaks" in the low energy region, partially cut-off, appear due to Compton scattering and registration of the gamma rays with lower energy (Table 1). This region, as well as the region after $796 \mathrm{keV}$ (registration of more energetic gamma rays and summing effect) will be considered in a further study.

Although detector 4 participates in both selected pairs, sum spectra for the 46 detector pair (Fig. 5), in the energy range from 200 to $3000 \mathrm{keV}$ (from 2 to 255 channel), showed number of counts in the peak regions higher than the pair 45. In the integral mode (Fig. 5a), the $605 \mathrm{keV}$ and $796 \mathrm{keV}$ peak regions contained 9639 486 and 5736513 counts, respectively, while in the non-coincident mode (Fig. 5b) and the mode of double coincidences (Fig. 5c) - 5703381 and 3623689,3 590996 and 1898127 counts, respectively. It could be explained by the fact that the sixth one is the detector on which the source was placed, and it generally shows the highest number of counts in the peak regions [6].

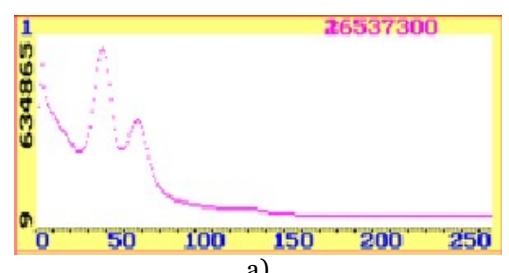

a)

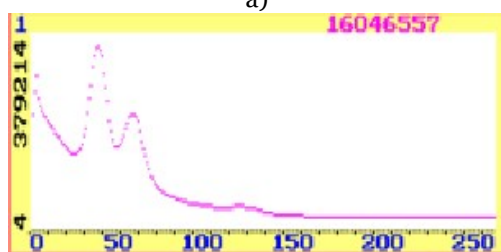

b)

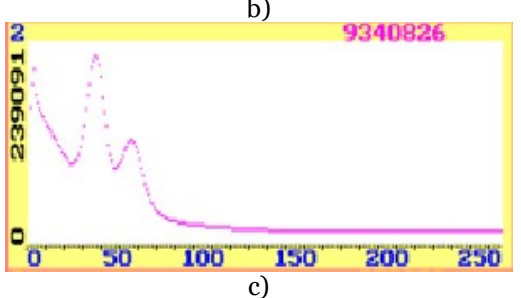

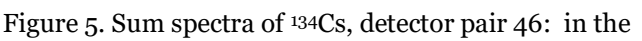
integral mode of counting (a), in the non-coincident mode of counting (b), in the mode of double coincidences (c)

It is important to point out that the region of the $605 \mathrm{keV}$ photopeak, in the presence of ${ }^{226} \mathrm{Ra}$ and ${ }^{232} \mathrm{Th}$ will be the unresolved peak containing $605 \mathrm{keV}$ from

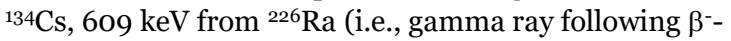
decay of ${ }^{214} \mathrm{Bi}$, with a relative intensity of $46.1 \%$ ), and $583 \mathrm{keV}$ from ${ }^{232} \mathrm{Th}$ (i.e., gamma ray following $\beta$-decay 
of $\left.{ }^{208} \mathrm{Tl}\right)$ - in the integral, non-coincident and the mode of double coincidences [7]. The $662 \mathrm{keV}$ gamma ray from ${ }^{137} \mathrm{Cs}$ creates a close peak, as well - in the integral and non-coincident spectra.

On the other hand, the peak at energy of $796 \mathrm{keV}$ is clear, particularly in the mode of double coincidences which previously showed the best signal-to-noise ratio - in both the (200-2000) $\mathrm{keV}$ and (300-3000) $\mathrm{keV}$ energy region (see, for example, [7]). Therefore, a future development of the coincident method for ${ }^{134} \mathrm{Cs}$ measurement in environmental samples should be based on analysing $796 \mathrm{keV}$ photopeak in coincidence spectra, which is in concordance with findings of the other researchers (see, for example, [8]).

\section{REGISTRATION EFFICIENCIES}

Photoefficiency (i.e., efficiency of registration in the full absorption peak) was determined from the spectral data using

$$
\varepsilon=\frac{\mathrm{N}_{\mathrm{c}}}{\mathrm{IA}},
$$

where $\mathrm{N}_{\mathrm{c}}$ is the counting rate (after the background subtraction), I - gamma ray intensity, and A - activity of the ${ }^{134} \mathrm{Cs}$ source. Experimental photoefficiencies for the single detectors and detector pairs are presented in Table 2.

Table 2. Efficiencies from individual and sum spectra in three modes of counting

\begin{tabular}{|c|c|c|}
\hline Detector/pair & $\varepsilon_{605}$ & $\varepsilon_{796}$ \\
\hline Integral mode & 0.058 & 0.041 \\
4 & 0.033 & 0.025 \\
5 & 0.073 & 0.054 \\
6 & 0.093 & 0.063 \\
45 & 0.131 & 0.089 \\
46 & & \\
Non-coincident mode & 0.035 & 0.027 \\
4 & 0.018 & 0.015 \\
5 & 0.044 & 0.035 \\
6 & 0.053 & 0.039 \\
45 & 0.077 & 0.056 \\
46 & & \\
4 & 0.023 & 0.014 \\
5 & 0.014 & 0.009 \\
6 & 0.027 & 0.017 \\
45 & 0.036 & 0.022 \\
46 & 0.049 & 0.029 \\
\hline
\end{tabular}

An average the $605 \mathrm{keV}$ photoefficiency for individual detectors was found to be 0.055 in the integral mode of counting, 0.032 in the non-coincident mode of counting, and 0.021 in the mode of double coincidences. Two considered detector pairs (45 and 46) showed the average $605 \mathrm{keV}$ photoefficiency of $0.112,0.065$ and 0.042 , respectively.
In regards to the $796 \mathrm{keV}$, an average photoefficiency of individual detectors was found to be 0.04 in the integral mode of counting, 0.026 in the non-coincident mode of counting and 0.013 in the mode of double coincidences. The detector pairs 45 and 46 , showed the $796 \mathrm{keV}$ photoefficiency in an average of $0.076,0.048$ and 0.026 , respectively.

For a comparison, the previous analysis of two $\mathrm{NaI}(\mathrm{Tl})$ detectors in the same system, at an angle of $180^{\circ}$, in sum integral, non-coincident and spectrum of double coincidences showed the detection efficiency of $0.106,0.067$ and 0.042 , respectively $(605 \mathrm{keV})$, and $0.074,0.035$ and 0.018 , respectively (796 keV) [5]. As it can be seen from Table 2, the detector pair 46 (the angle between detectors $\sim 90^{\circ}$ ) is more efficient in registration both gamma rays $-605 \mathrm{keV}$ and $796 \mathrm{keV}$, in all the modes of counting.

Ratios of the total and photopeaks count rates in the ${ }^{134}$ Cs spectrum and under the corresponding energy region in the background spectrum are given in Table 3 (individual detectors) and Table 4 (detector pairs 45 and 46). It should be noted that, as abovementioned,

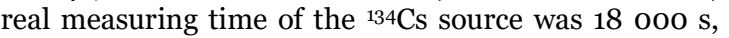
while the background spectra were acquired over the time corresponding to the ${ }^{134} \mathrm{Cs}$ live time of measurements.

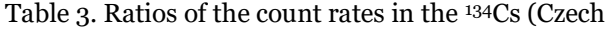
Metrology Institute, 9031 - OL - 471/o6) spectrum and under the corresponding energy region in the background spectrum in different modes of counting ([1-6] - integral, [1-1] - non-coincidence, [2-2] - double coincidences - individual detectors

\begin{tabular}{|c|c|c|c|}
\hline $\begin{array}{c}\text { Mode of } \\
\text { counting }\end{array}$ & $\begin{array}{c}\text { Ratio of the } \\
\text { total count } \\
\text { rates: } \\
\text { 134Cs/ } \\
\text { background }\end{array}$ & $\begin{array}{c}\text { Ratio of the } \\
\text { count rates } \\
\text { in the 605 } \\
\text { keV region: } \\
\text { 134Cs/ } \\
\text { background }\end{array}$ & $\begin{array}{c}\text { Ratio of the } \\
\text { count rates } \\
\text { in the 796 } \\
\text { keV region: } \\
\text { 134Cs/ } \\
\text { background }\end{array}$ \\
\hline $\begin{array}{c}\text { Detector } 4 \\
{[1-6]}\end{array}$ & 577 & 1085 & 1128 \\
{$[1-1]$} & 446 & 807 & 1041 \\
{$[2-2]$} & 1323 & 2479 & 2484 \\
\hline $\begin{array}{c}\text { Detector } 5 \\
{[1-6]}\end{array}$ & 372 & 782 & 780 \\
{$[1-1]$} & 276 & 581 & 637 \\
{$[2-2]$} & 762 & 1616 & 1464 \\
\hline Detector 6 & 627 & 1432 & 1487 \\
{$[1-6]$} & 481 & 1135 & 1170 \\
{$[1-1]$} & 1518 & 3561 & 3202 \\
{$[2-2]$} & \multicolumn{3}{|r}{} \\
\hline
\end{tabular}

In comparison to the integral mode of counting, the $605 \mathrm{keV}$ and $796 \mathrm{keV}$ photopeak detection efficiency of the individual detectors and their pairs (Table 2) when counting non-coincident pulses and double coincidences - decreases, while the background count rate in the same regions decreases by a larger factor. The ratios given in Table 3 , show that the mode of double coincidences is optimal for determining ${ }^{134} \mathrm{Cs}$ activity. Individual detectors and the detector pairs showed better sensitivity, i.e., signal/noise ratio in the spectra of double coincidences significantly better than in the other considered modes of counting (integral, 
and non-coincident). Therefore, although some advantages of the integral, in compare to noncoincident mode of counting can be seen from Table 3 and Table 4, further the method development should be focused on a coincidence mode of counting, preferable of double coincidences, which are the most intense.

Table 4. Ratios of the count rates in the ${ }^{134 \mathrm{Cs}}$ (Czech Metrology Institute, 9031 - OL - 471/o6) spectrum and under the corresponding energy region in the background spectrum in different modes of counting ([1-6] - integral, [1-1] - non-coincidence, [2-2] - double coincidences - sum spectra of detector pairs 45 and 46 in the energy range (200-3000) $\mathrm{keV}$

\begin{tabular}{|c|c|c|c|}
\hline $\begin{array}{c}\text { Mode of } \\
\text { counting }\end{array}$ & $\begin{array}{c}\text { Ratio of the } \\
\text { total count } \\
\text { rates: } \\
\text { 134Cs / } \\
\text { background }\end{array}$ & $\begin{array}{c}\text { Ratio of the } \\
\text { count rates } \\
\text { in the 605 } \\
\text { keV region: } \\
\text { 134Cs / } \\
\text { background }\end{array}$ & $\begin{array}{c}\text { Ratio of the } \\
\text { count rates } \\
\text { in the 796 } \\
\text { keV region: } \\
\text { 134Cs / } \\
\text { background }\end{array}$ \\
\hline $\begin{array}{c}\text { Pair 45 } \\
{[1-6]}\end{array}$ & 513 & 950 & 981 \\
{$[1-1]$} & 404 & 727 & 838 \\
{$[2-2]$} & 1081 & 2100 & 1990 \\
\hline Pair 46 & 696 & 1282 & 1364 \\
{$[1-6]$} & 551 & 1016 & 1122 \\
{$[1-1]$} & 1552 & 3075 & 3028 \\
{$[2-2]$} & \multicolumn{3}{|c}{} \\
\hline
\end{tabular}

\section{CONCLUSIONS}

Obtained spectra showed relatively high registration efficiency of individual detectors and two detector pairs at an angle of $90^{\circ}$ from the PRIPYAT-2M spectrometer - for the ${ }^{134} \mathrm{Cs}$ gamma rays in the integral, non-coincident and mode of double coincidences. Presented results are baselines for further development of the coincidence method for ${ }^{134}$ Cs measurement - using multidetector systems with measuring geometry close to $4 \pi$, with the $796 \mathrm{keV}$ photopeak in a coincidence mode as appropriate for

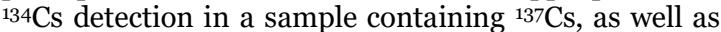
decay products of ${ }^{226} \mathrm{Ra}$ and ${ }^{232} \mathrm{Th}$.

\section{REFERENCES}

1. Y. Unnoa, T. Sanamib, M. Hagiwarab, S. Sasakib, A. Yunokia, "Application of beta coincidence to nuclide identification of radioactive samples contaminated by the accident at the Fukushima Nuclear Power Plant," Prog. Nucl. Sci. Tech., vol. 4, pp. 90 - 93, 2014. DOI: $10.15669 /$ pnst. 4.90

2. Recommended data, LNHB, Paris, France, 2017. Retrieved from: http://www.nucleide.org/DDEP WG/ DDEPdata.htm;

Retrieved on: Jan. 15, 2018

3. E. L. Grigorescu, P. de Felice, A. C. Razdolescu, A. Luca, "Low-level gamma spectrometry using beta coincidence and Compton suppression," Appl. Radiat. Isot., vol. 61, no. 2-3, pp. 191 - 195, Aug-Sep. 2004.

DOI: $10.1016 /$ j.apradiso.2004.03.044 PMid: 15177343

4. С. К. Андрухович, А. В. Берестов, В. И. Гутко, А. М. Хильманович, "Высокочувствительные многодетекторные гамма спектрометры ПРИПЯТЬ,” Препринт Института физики, АН БССР, Минск, Беларусь, 1995 (S. K. Andrukhovich, A. V. Berestov, V. I. Gutko, A. M. Hil'manovich, "High sensitive multidetector gamma spectrometers PRIPYAT," Preprint of the Institute of Physics, AN BSSR, Minsk, Belarus, 1995.)

5. N. Svrkota, N. M. Antović, T. Andjelić, "Osnovi koincidentnog metoda mjerenja cezijuma-134," u Černobilj, 30 godina posle, G. Pantelić, Ur., Beograd, Srbija: Društvo za zaštitu od zračenja Srbije i Crne Gore i Institut Vinča, str. 278 - 286, 2016. (N. Svrkota, N. M. Antović, T. Andjelić, "Basic research for coincidence method of Cs-134 measurement," in Chernobyl, 30 years after, G. Pantelić, Ed., Belgrade, Serbia: Society for Radiation Protection of Serbia and Montenegro and Vinča Institute, 2016, pp. 278 - 286.) Retrieved from: https://www.researchgate.net/publicat ion/309772261 Cernobilj_30 godina_posle;

Retrieved on: Jan. 15, 2018

6. J. Mijušković, "Efikasnost detekcije ${ }^{134 C s}$ parovima detektora pod uglom od $90^{\circ}$ i $180^{\circ}$," Spec. rad, Univerzitet Crne Gore, Prirodno-matematički fakultet, Podgorica, Crna Gora, 2016. (J. Mijušković, "Detection efficiency of ${ }^{134 \mathrm{Cs}}$ by detector pairs at angles of $90^{\circ}$ and $180^{\circ}$, Spec. Thesis, University of Montenegro, Faculty of Natural Sciences and Mathematics, Podgorica, Montenegrom 2016.)

7. N. M. Antović, N. Svrkota, "Detection efficiencies of ${ }^{226} \mathrm{Ra}$ and ${ }^{232} \mathrm{Th}$ in different modes of counting of the PRIPYAT-2M spectrometer," Nucl. Technol. Radiat. Prot., vol. 24, no. 2, pp. 109 - 118, Jul. 2009. DOI: $10.2298 /$ NTRPo902109A

8. M. C. Cook, M. J. Stukel, W. Zhang, J.-F. Mercier, M. W. Cooke, "The determination of Fukushimaderived cesium-134 and cesium-137 in Japanese green tea samples and their distribution subsequent to simulated beverage preparation," J. Environ. Radioactiv., vol. 153, pp. 23 - 30, Mar. 2016.

DOI: 10.1016/j.jenvrad.2015.12.010

PMid: 26714059 